\title{
LA INVERSIÓN EXTRANJERA EN CUBA
}

\author{
Por: Felipe Merlano de la Ossa*
}

Definitivamente la República de Cuba entró en la moda de la internacionalización

modernización de su economía. Quién lo diría!, el mismo Fidel Castro le ha abierto las puertas a la inversión extranjera proveniente del mundo capitalista, en unas condiciones tales, que le hacen exclamar al economista Jorge Child: "No creo que exista una ley más generosa para la inversión extranjera en país alguno".

En efecto, la Asamblea Nacional del Poder Popular de la República de Cuba, en su sesión del 5 de septiembre de 1995, aprobó la Ley $N^{\circ} 77$, más conocida como la Ley de la Inversión Extranjera. Las razones para tomar esta histórica y trascendental decisión fueron:

La carencia de Capital, de determinadas tecnologías y algunas veces- de mercados, y la necesidad de reestructurar. su industria, sobre todo en un escenario mundial $\sin$ la existencia del campo socialista y bajo los signos de una economía mundial globalizada y con fuertes tendencias hegemónicas en 10 económico y político.

Con estos cambios se busca obtener importantes beneficios para la economía cubana y su comunidad. Entre Ellos, la introducción de tecnologías novedosas y de punta, mayor eficiencia productiva, la creación de nuevos puestos de trabajo, mejoramiento de la calidad de los productos y servicios que se ofrecen, reducción de los costos de producción, mayor competitividad en el exterior y el acceso a determinados mercados. Todo esto, claro está, sobre la base de un estricto respeto a la independencia y soberanía nacional.

Esta Ley es resultado de un proceso que se viene gestando desde comienzos del noveno decenio de este siglo. Las bases jurídicas de la Ley 77 se 
encuentran en la Reforma Constitucional de 1992, a través de la cual se reconoció la propiedad sobre empresas mixtas, sociedades y asociaciones económicas que se conformen de acuerdo con la ley. Es más, en los considerandos de la Ley de Inversión Extranjera en Cuba, se puede leer la posibilidad de adelantar privatizaciones sobre propiedades del estado.

En este proceso de fortalecer la capacidad económica y fomentar el desarrollo sostenible de Cuba, el Gobierno Nacional le ofrece a los inversionistas extranjeros plena protección y seguridad sobre sus inversiones. Aquí hay un pequeño impase que se supera a través de la firma de convenio de seguros, nos referimos a la posibilidad de expro piación en caso de utilidad pública o interés social.

Por otro lado, un grupo notable de empresas norteamericanas ha empezado a mostrar interés en que se levante el embargo a Cuba y en invertir en la isla. La presión radica en que mientras otros países se benefician de las ventajas que ofrece este mercado emergente, ellos (los marginando de un espléndido negocio. Todo esto parece indicar que a Washington Le suena, le suena esta idea y aunque insisten en mantener el bloqueo, sorprenden con algunas decisiones como la de permitir que los cubanos - americanos puedan viajar al menos una vez al año a la isla y los órganos de prensa estado unidenses puedan abrir oficinas en La Habana. La normalización de las relaciones entre Estados Unidos y Vietnam parece ser un elemento que hace pensar que el momento adecuado para negociar con Cuba está hoy más cerca que en cualquier momento en los últimos 33 años.

Las cifras de inversión extranjera en "la fruta prohibida del caribe", desde 1990 hasta septiembre de 1995, superar. los US $\$ 550$ millones, distribuidos así: España US\$125, México US\$100; Italia US\$87; Otros US\$85; Canadá US $\$ 65$; Gran Bretaña US $\$ 50$ y los Países Bajos US\$40. Esta afluencia de capitales parece ser la tabla de salvación para la débil economía cubana. El cambio en el producto interno bruto real (crecimiento económico) en el último quinquenio, refleja el quiebre de una grave tendencia 
recesiva; en efecto, en 1990 el crecimiento fue negativo en algo más del 3\%; en 1991 el crecimiento negativo alcanzó el $10 \%$; en 1992 se acercó al $12 \%$ y en 1993 superó el 15\%; mientras que en 1994 se registró, por primera vez en ese período, un crecimiento positivo del $0.7 \%$.

Ahora bien, parte importante de esta inversión se está dirigiendo al turismo. La situación desesperada del gobierno por obtener divisas, generar empleo y reactivar la economía; así como sus atractivos físicos y su cultura en el manejo de esta clase de servicios, convierten a la isla en un gran competidor -aun que sea en lo mediato- en el mercado turístico internacional.

Esto debe generar estudios y estrategias por parte del sector turís tico de Cartagena, ya que los precios relativos, la novedad, lo diferente y lo desconocido de Cuba, podrían causar un desplazamiento del flujo de turistas extranjeros que llegan a nuestra ciudad, hacia Cuba.

Aunque la ley de inversión extranjera en la isla es muy limitada, produce (todavía) recelos y los capitales no han llegado en forma masiva, si es bueno que nuestros empresarios empiecen a pensar y actuar con respecto a la nueva competencia. Camarón que se duerme,.........

* El autor es EconomistaDocente de la Facultad de Ciencias Económicas de la Universidad de Cartagena y se desempeña como Director Económico y Administrativo de la Cámara de Comercio de Cartagena. 